\title{
Correctness in Power Factor of Induction Motor by using Active Filters
}

\begin{abstract}
This paper proposes a novel method of correcting power factor of an induction motor by the making the use of active power filters. In the electrical power system mostly $80 \%$ to $85 \%$ power factor is reduced by using induction motor as a load in various industries for acting as a prime mover. The induction motor running with a little power factor may cause power quality problems in the electrical power system. Due to very little power factor the load draws high starting current from the electrical grid, this causes various problems like voltage fluctuation, voltage sag and sometimes warmth the winding of the induction machine. Therefore, it is required to develop a method which uses active filters for improving the power factor of the induction motor.
\end{abstract}

Vinay Anand

Keywords- Power factor correctness, induction machine, improved power quality, active power filters.

\section{INTRODUCTION}

With the rapid increase in inductive load from past few years, it is very difficult for power stations to maintain the power factor to unity [1]. Due to the increasing of inductive appliances like as induction motor almost $85 \%$ of power factor is drained by these types of loads [2],[3]. In many developing countries, three phase induction motor works as a prime mover for rotating several types of electrical equipment and in some places, it acts as a water or fuel pump for pumping out water or any other form of liquid from deep well or storage unit. "The induction motor is an electrical device which is used to convert electrical energy into rotational energy" [4],[5]. It is assumed that during running of induction motor the power factor of the motor is reduced thereby reducing the power quality of the system.

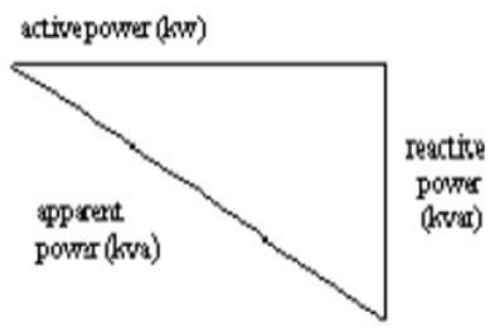

Fig. 1: Powrer triangle in terms of power

From the figure,

$$
\begin{aligned}
& (\mathrm{KVA})^{2}=(\mathrm{KW})^{2}+(\mathrm{KVAR})^{2} \\
& \text { Power factor } \cos \phi=\frac{\text { actve power }}{\text { apparent power }}=\frac{\mathrm{KW}}{\mathrm{KVA}}
\end{aligned}
$$

\section{WORKING OF INDUCTION MOTOR AT LOW POWER FACTOR}

The induction motor never runs at the unity power factor due to which it exhibits several types of losses thereby dropping the voltage of the system. When the induction motor runs at power factor lower than 1, it draws high current from the power source [6]. This high current flowing in the coil of induction motor will reduce the performance and efficiency by creating heat inside it. Thus, it is required to improve the power quality of the motor so that maximum power can be transferred from source to load without involving in power quality problems [7]. The power factor is defined as "the phase angle between voltage current" [8]. For unity power factor the phase angle between voltage and current must be 0 [9]. But in practice it is not possible to do so, therefore it is required to improve the power factor near to the unity. This improvement of power factor can be done by using active series filters. The main advantages of using active series filters is that it is compact in size and performs the power factor corrections by placing it to the series to the power system. It compensates the unwanted current and improves the power factor of the inductive load [10].

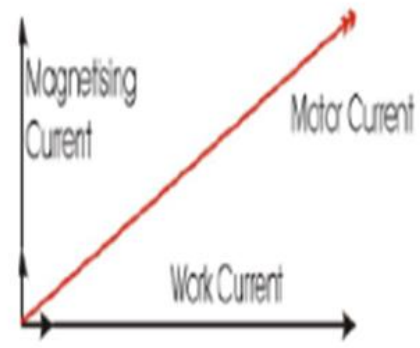

Fig. 2: Current components of an induction motor:

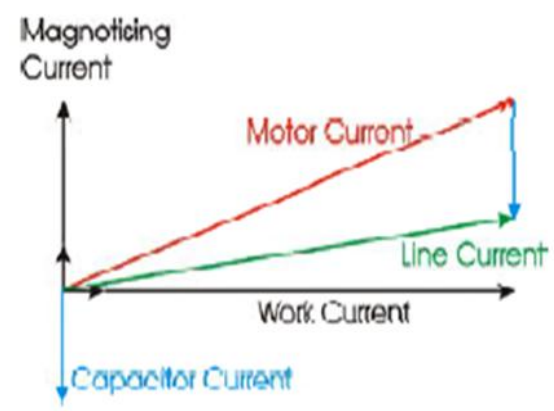

Fig. 3: Current components after adding capacitor.

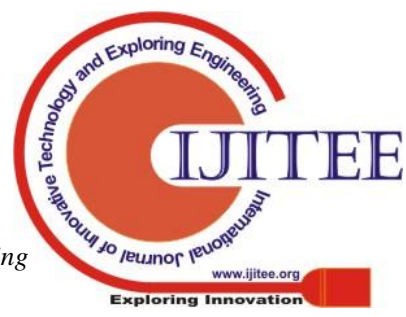




\section{SIMULINK MODELING AND RESULTS}

The simulated prototype of the three-phase induction machine without series filter compensation and with series filter for power factor correction is shown in fig.4 and fig.5. this simulation shows the model of power system supplying power from source to load by using three phase transformers. The three-phase induction motor behaves as an inductive load in various industries.

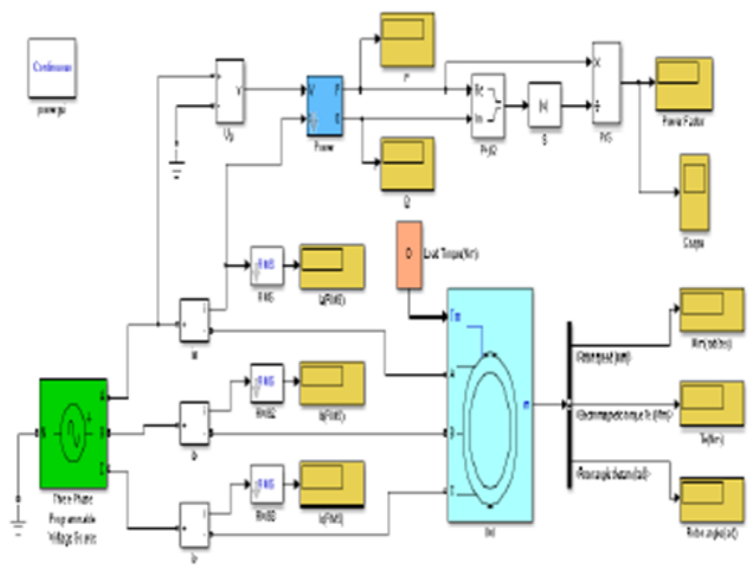

Fig. 4: Simulink model of a 3-Phase Induction Motor

The simulated structure of a three-phase induction motor is designed in MATLAB software without including series filters. In this model the three phase induction motor runs with lagging power factor and the output waveform is fluctuating in nature.

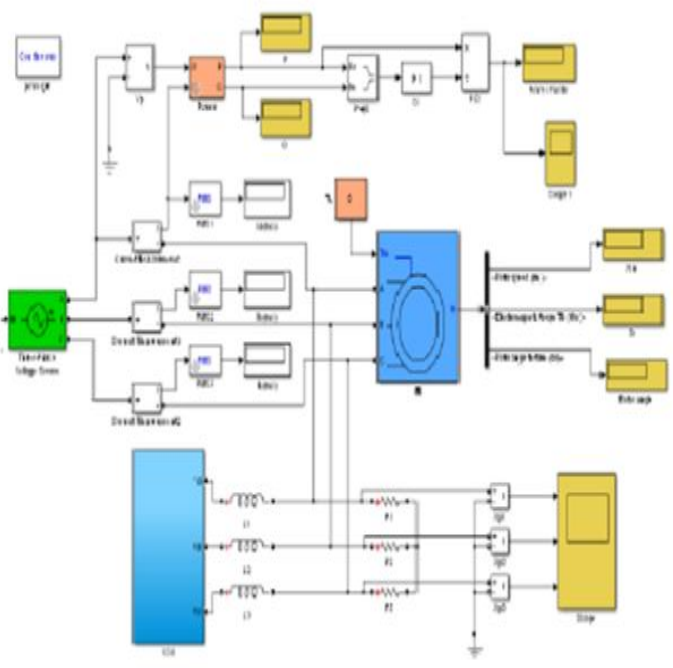

Fig. 5: Simulink model of a 3-Phase Induction Motor Using Active Power Filter

In fig. 5 the model of three phase induction motor with series active filter is shown. From the above figures it is clear that the output waveform produced before employing active filters is varying in nature and the waveform obtained after employing active series compensation has improved power factor waveform.
Table 1: Comparison of Power Factor without any compensation and with Active Power Filter

\begin{tabular}{|l|l|c|c|}
\hline $\begin{array}{c}\text { Sr. } \\
\text { no }\end{array}$ & $\begin{array}{c}\text { Motor Load } \\
\text { Factor }\end{array}$ & $\begin{array}{c}\text { Power Factor } \\
\text { without } \\
\text { compensation }\end{array}$ & $\begin{array}{c}\text { Power Factor with } \\
\text { active power filter } \\
\text { compensation }\end{array}$ \\
\hline 1 & Unloaded & 0.15 & 0.998 \\
\hline 2 & $1 / 4$ loaded & 0.62 & 0.998 \\
\hline 3 & $1 / 2$ loaded & 0.82 & 0.998 \\
\hline 4 & $3 / 4$ loaded & 0.86 & 0.998 \\
\hline 5 & Full loaded & 0.89 & 0.998 \\
\hline 6 & Overloaded & 0.91 & 0.998 \\
\hline
\end{tabular}

The comparision table 1 , describes the induction motor without compansation of power fator and compensated power factor of induction motor. It is observed that when the motor gets started without load the power factor without sereis filters is seen to be 0.15 and after placing active power filter it is seen to be 0.99 . When the motor runs with full load, it is seen that without filter the power factor is 0.89 and after series filter it is assumed to be 0.99 .

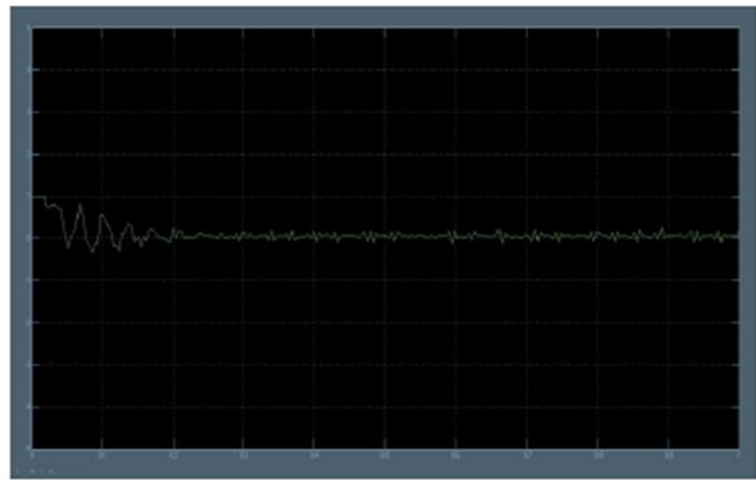

Graph 1: Plot of pf without compensation

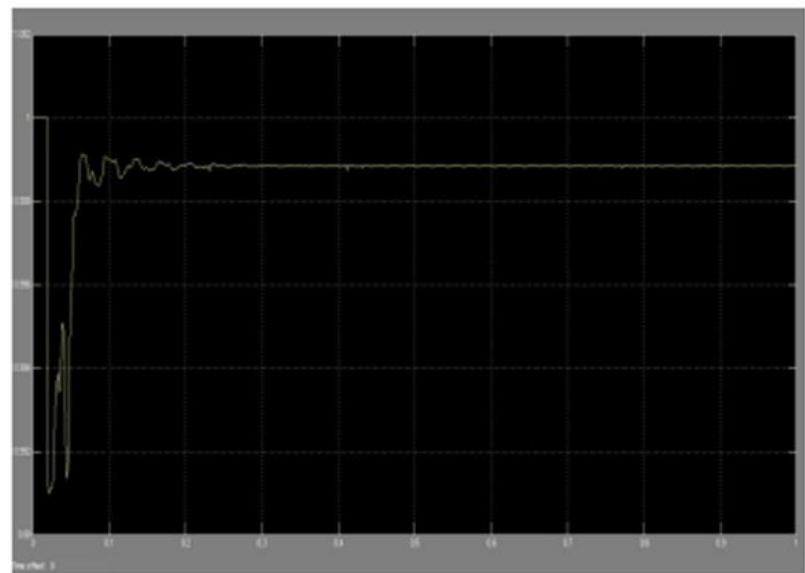

Graph 2: Plot of pf with active power filter compensation

\section{CONCLUSION}

In this paper, the MATLAB simulation model of power system connected induction motor is designed with and without applying series active filters. It is absorbed that when running induction motor without series active filters the power factor is very poor. And when the active series filter is connected to the load side, the power factor is improved and reaches near the unity. Hence, from the above

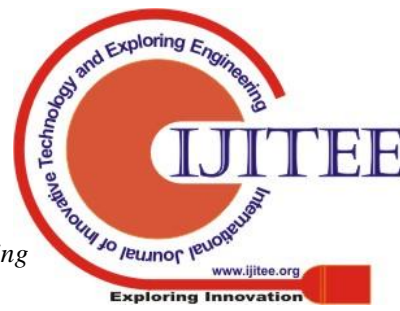


MATLAB simulation result it is clear that by applying the series compensation circuit, the power quality of the system gets improved. The reduced power factor effects the system by reducing performance and efficiency of the load. Reduced amount of power factor also creates harmonics problem in the system and numerous of other types of power quality issues. Thus, to reduce or eliminate the problem of harmonics, a system is successfully developed that is capable of improving the power quality of induction motor.

\section{REFERENCES}

1. A. Rand, M. Dixon-Woods, and G. P. Martin, "Does quality improvement improve quality?," Futur. Hosp. J., 2016.

2. E. Waffenschmidt and T. Staring, "Limitation of inductive power transfer for consumer applications," in 13th European Conference on Power Electronics and Applications (EPEC), 2009.

3. D. $\mathrm{t}$ Vaghela and D. $\mathrm{m}$ Bhankhodiya, "Active Filters for Power Quality Improvement,” Indian J. Appl. Res., 2014.

4. A. Boglietti, "Induction Motor," 2011.

5. J. Bird, "Three-phase induction motors," in Electrical and Electronic Principles and Technology, 2018.

6. M. A. S. Masoum and E. F. Fuchs, "Modeling and Analysis of Induction Machines," in Power Quality in Power Systems and Electrical Machines, 2015.

7. K. L. Shi, T. F. Chan, Y. K. Wong, and S. L. Ho, "Modelling and Simulation of the Three-Phase Induction Motor Using Simulink," Int. J. Electr. Eng. Educ., 2013.

8. C. Kitcher, "Power Factor," in Electrical Installation Calculations: Basic, 2018.

9. I. Batarseh and H. Wei, "Power factor correction circuits," in Power Electronics Handbook, 2011.

10. P. Kumar and A. Mahajan, "Soft computing techniques for the control of an active power filter," IEEE Trans. Power Deliv., 2009. 